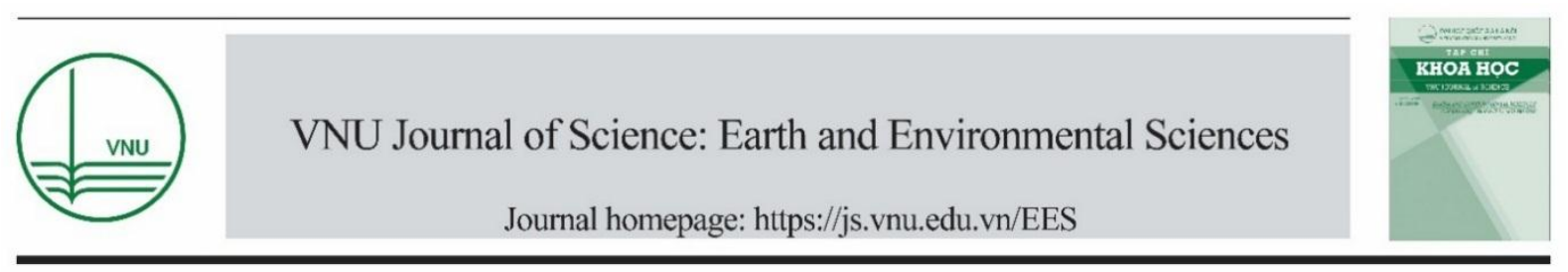

\title{
Original Article \\ Application of SAR Sentinel-1 Satellite for Air Emission Inventory from Rice Straw Open Burning in Hanoi
}

\author{
Hoang Anh Le ${ }^{1, *}$, Nguyen Viet Thanh ${ }^{1}$, Do Minh Phuong ${ }^{2}$, Ho Quoc Bang ${ }^{3}$, \\ Nguyen Quang Hung ${ }^{1}$, Dinh Manh Cuong ${ }^{1}$ \\ ${ }^{I}$ VNU University of Science, Vietnam National University, 334 Nguyen Trai, Thanh Xuan, Hanoi, Vietnam \\ ${ }^{2}$ Center for Informatics and Statistics (CIS), Ministry of Agriculture and Rural Development (MARD) \\ 2 Ngoc Ha, Ba Dinh, Hanoi, Vietnam. \\ ${ }^{3}$ Institute for Environment and Resources, Vietnam National University, Ho Chi Minh City, Vietnam \\ 142 To Hien Thanh, 10 District, Ho Chi Minh City, Vietnam
}

Received 19 May 2020

Revised 15 July 2020; Accepted 04 August 2020

\begin{abstract}
Air emission inventory is an advance tool in application research of environmental field. Emission inventory can be conducted in different approaches, in which statistical data collection is considered to be a conventional way with relatively low reliability and delaying time. This study uses a methodology of extracting activity data of cultivation area and rice production employing SAR Sentinel-1 images in order to overcome the limitation of conventional method. Consequently, the data is utilized to estimate the total air pollutants emitted from rice straw open burning. Results show that integration of remote sensing data (SAR Sentinel-1 satellite) improves the seasonal spatial rice cultivated area and production distribution with high reliability. The study implies a considerable potential of satellite data for estimation of air emission from agriculture waste combusion due to its availability, real-time, and low cost features. Application for Hanoi in 2019 performs that an amount of 460 thousand tons of rice straw was burned, thus, created 542 thousand tons of $\mathrm{CO}_{2}(90 \%), 42$ thousand tons of $\mathrm{CO}(7 \%)$, and other air pollutants of the rest $3 \%$.
\end{abstract}

Keywords: SAR, sentinel, emission inventory, rice straw.

\footnotetext{
${ }^{*}$ Corresponding author.

E-mail address: leha@vnu.edu.vn
}

https://doi.org/10.25073/2588-1094/vnuees.4635 


\title{
Kiểm kê khí thải phát sinh do đốt rơm rạ ngoài đồng ruộng trên địa bàn thủ đô Hà Nội bằng ứng dụng vệ tinh SAR Sentinel-1
}

\author{
Hoàng Anh Lể, ${ }^{1, *}$ Nguyễn Việt Thanh ${ }^{1}$, Đỗ Minh Phương ${ }^{2}$, Hồ Quốc Bằng ${ }^{3}$, \\ Nguyễn Quang Hưng ${ }^{1}$, Đinh Mạnh Cường ${ }^{1}$ \\ ${ }^{1}$ Truoòng Đại học Khoa học Tụ nhiên, Đại học Quốc gia Hà Nội \\ 334 Nguyễn Trãi, Thanh Xuân, Hà Nội, Việt Nam \\ ${ }^{2}$ Trung tâm Tin học và Thống kê, Bộ Nông nghiệp và Phát triển Nông thôn \\ Số 2 Ngọc Hà, Ba Đình, Hà Nội, Việt Nam \\ ${ }^{3}$ Viện Môi truờng và Tài Nguyên, Đại học Quốc gia Hồ Chí Minh \\ 142 Tô Hiến Thành, Quận 10, thành phố Hồ Chí Minh, Việt Nam \\ Nhận ngày 19 tháng 5 năm 2020 \\ Chỉnh sửa ngày 15 tháng 7 năm 2020; Chấp nhận đăng ngày 04 tháng 8 năm 2020
}

\begin{abstract}
Tóm tắt: Nghiên cứu này trình bày phương pháp trích xuất dữ liệu về diện tích và năng suất lúa thông qua việc sử dụng ảnh vệ tinh SAR Sentinel-1 để ước tính lượng khí thải phát sinh từ hoạt động đốt rơm rạ trên đồng ruộng. Kết quả cho thấy rằng việc kết hợp dữ liệu viễn thám (từ ảnh vệ tinh SAR Sentinel-1) có thể cải thiện được sự phân bố không gian về diện tích và sản lượng lúa theo mùa vụ với độ tin cậy cao. Dựa trên những kết quả này, dữ liệu vệ tinh cho thấy tiềm năng lớn để ước tính lượng khí thải phát sinh từ hoạt động đốt rơm rạ ngoài đồng ruộng, có lợi thế về tính sẵn có, kịp thời và khả năng cạnh tranh vì chi phí thấp. Theo kết quả tính toán được vào năm 2019, với lượng rơm rạ thải bỏ và bị đem đốt trên đồng ruộng ở địa bàn thủ đô Hà Nội vào khoảng 460 nghìn tấn, tạo ra tổng lượng chất gây ô nhiễm lớn với 542 nghìn tấn $\mathrm{CO}_{2}$ (chiếm $90 \%$ ), 42 nghìn tấn $\mathrm{CO}$ (chiếm khoảng $7 \%$ ), những khí thải khác chỉ chiếm $3 \%$ còn lại.
\end{abstract}

Tù khóa: SAR, sentinel, kiểm kê khí thải, đốt rơm rạ.

\section{Mở đầu}

Sinh khối (biomass) là nguồn năng lượng tích tụ từ ánh sáng mặt trời qua hoạt động quang hợp của cây xanh, là nguồn năng lượng chính cung cấp cho các hoạt động sống của con người và sinh vật trên Trái đất. Phát thải từ quá trình đốt cháy sinh khối là một trong những nguồn đóng góp các chất gây ô nhiễm không khí, có tác động đáng kể đến phản ứng hóa học khí quyển toàn cầu và gây biến đổi khí hậu [1-3]. Đốt phế phụ phẩm nông nghiệp, đặc biệt là hoạt động đốt rơm rạ sau mỗi vụ mùa thu hoạch đã góp phần đáng kể vào ô nhiễm môi trường và gây ra các tác động xấu đến sức khỏe cộng đồng địa phương và khu vực [3-6].

Hà Nội là vùng trồng lúa chính của đồng bằng sông Hồng với diện tích, năng suất lúa cao.

\footnotetext{
"Tác giả liên hệ.

Địa chi email: leha@vnu.edu.vn

https://doi.org/10.25073/2588-1094/vnuees.4635
} 
Song song với sự phát triển của sản xuất lúa gạo, Hà Nội cũng tạo ra một lượng phế phụ phẩm rất lớn, bao gồm một phần quan trọng là rơm rạ thường xuyên được đốt cháy trên các cánh đồng sau khi thu hoạch. Rơm rạ có thể chưa khô hoàn toàn khi đốt tạo thành những đám khói bao trùm một vùng rộng lớn, ảnh hưởng đến chất lượng môi trường, sức khỏe người dân sống quanh khu vực và là nguy cơ gây mất an toàn giao thông [2,3,7-9]. Khói rơm rạ cũng được cho là nguyên nhân gây ra rất nhiều bệnh tật có liên quan đến hệ hô hấp do gây ra tình trạng ngột ngạt, khó chịu đặc biệt là vào những ngày có thời tiết nắng nóng, oi bức [3,7-9]. Đốt rơm rạ được cho là nguyên nhân gây ra tình trạng khói mù dày đặc bao quanh thủ đô Hà Nội những ngày sau thu hoạch [2]. Đốt rơm rạ ngoài đồng ruộng là quá trình đốt cháy không hoàn toàn, thường không có hệ thống kiểm soát khí thải, do vậy đã làm phát sinh nhiều chất độc hại vào môi trường. Trong đó khí $\mathrm{CO}_{2}$, sản phẩm chủ yếu trong quá trình đốt được giải phóng vào khí quyển cùng với $\mathrm{CO}, \mathrm{CH}_{4}, \mathrm{NO}_{\mathrm{x}}, \mathrm{SO}_{2}$ và nhiều chất khác $[5,6,10]$. Các khí thải từ nguồn đốt rơm rạ là tác nhân gây hiệu ứng nhà kính như khí $\mathrm{CO}_{2}, \mathrm{CH}_{4}, \mathrm{~N}_{2} \mathrm{O}$. Các khí thải khác như $\mathrm{SO}_{\mathrm{x}}, \mathrm{NO}_{\mathrm{x}}$ có thể tích tụ trong khí quyển gây ra tình trạng mưa axit. Tuy vậy nguồn gây ô nhiễm không khí chủ yếu này vẫn chưa được chú trọng trong chương trình quản lý chất lượng không khí ở nhiều quốc gia. Việc định lượng khí thải được tạo ra bởi đốt cháy phế phụ phẩm nông nghiệp sẽ là cơ sở khuyến cáo cho hành động xây dựng chương trình, chính sách phù hợp về nâng cao chất lượng không khí quốc gia và hợp tác quốc tế trong kiểm soát có hiệu quả các khí thải từ nguồn này [10].

Hiện nay trên thế giới đã có rất nhiều công trình nghiên cứu về kiểm kê phát thải khí do đốt phế phụ phẩm nông nghiệp ngoài trời, trong đó có đốt rơm rạ ngay tại đồng ruộng. Nhưng các nghiên cứu đó vẫn chưa thể kiểm kê phát thải khí từ hoạt động đốt phế phụ phẩm ngoài trời một cách đầy đủ vì những khó khăn do thiếu nguồn dữ liệu hoạt động (activity data) được thống kê từ hoạt động đốt của người dân bản địa [9]. Các dữ liệu hoạt động trước đây chủ yếu dựa vào số liệu thống kê thì chưa đảm bảo độ tin cậy do hạn chế kinh phí, thiếu nguồn nhân lực thực hiện thống kê, thiếu tần suất quan sát thực tế khi mà dữ liệu chỉ được giám sát trực tiếp vào các năm có đuôi kết thúc là 1 hoặc 6 , chậm công bố $[2,9]$ đã dẫn đến thiếu tính thực tế trong nhiệm vụ kiểm soát, giảm thiểu tác động ô nhiễm không khí địa phương, vùng và khu vực. Bài toán đó buộc các nhà khoa học phải tìm ra phương pháp mới để có thể xây dựng được cơ sở dữ liệu với kinh phí ít tốn kém hơn, xác định nhanh hơn, sớm hơn và có độ tin cậy cao nhằm phục vụ công tác kiểm kê phát thải có thể dự báo được vấn đề ô nhiễm trong tương lai để từ đó có giải pháp đúng cho việc kiểm soát và nâng cao chất lượng không khí địa phương. Một trong những công cụ đó là sử dụng ảnh viễn thám với thế hệ vệ tinh mới: hệ thống radar khẩu độ tổng hợp giao thoa (Synthetic Aperture Radar - SAR). Công nghệ SAR sử dụng ảnh vệ tinh Sentinel đã được ứng dụng thành công trong một số lĩnh vực ở nước ta như ứng dụng để giải quyết bài toán ngập lụt [11], quản lý lưu vực hồ [12], giám sát lún sụt bề mặt đất [13], giám sát tài nguyên rừng [14]. Nghiên cứu này được tiến hành nhằm đánh giá việc ứng dụng công cụ viễn thám với ảnh vệ tinh SAR Sentinel-1A với mục đích đánh giá tình hình sản xuất lúa, hoạt động đốt rơm rạ trên đồng ruộng, ước tính được tổng lượng khí thải đặc trưng phát sinh từ hoạt động đốt rơm rạ trên đồng ruộng trên địa bàn thủ đô Hà Nội (TĐHN).

\section{Phương pháp nghiên cứu}

\subsection{Phương pháp uớc tính sản lương nông nghiệp qua ứng dụng công nghệ viễn thám}

Xuất phát từ nhu cầu được cung cấp dữ liệu một cách chính xác hơn về diện tích, sản lượng lúa từng vụ mùa của từng địa phương cho thống kê nông nghiệp và thực hiện chế độ an ninh lương thực, bảo hiểm mùa màng và quản lý môi trường. Giám sát lúa gạo đã được thực hiện trên toàn thế giới như một nhiệm vụ giám sát cây trồng hoặc trong các quy trình quản lý sử dụng đất. Để thu thập thông tin về diện tích trồng lúa, 
nhiều quốc gia và tổ chức đã phát triển các hệ thống giám sát lúa gạo qua vệ tinh [15]. Kỹ thuật giám sát dữ liệu ngành nông nghiệp trồng lúa phổ biến hiện nay bao gồm khảo sát trực tiếp, sử dụng mô hình thống kê, phân tích dựa trên nền ảnh viễn thám hoặc kết hợp đồng thời các công cụ đó để cho độ chính xác cao hơn [16]. Công cụ viễn thám dựa trên nền ảnh vệ tinh với hình ảnh vệ tinh quan sát Trái đất và kỹ thuật xử lý hình ảnh kỹ thuật số cung cấp một phạm vi rộng để theo dõi cây trồng từ quốc gia này sang quốc gia khác, hoặc thậm chí ở cấp hành chính nhỏ hơn như quận, huyện [17]. Hiện nay công việc này đã có thuận lợi hơn nhiều khi mà dữ liệu vệ tinh đã được cung cấp miễn phí cho người dùng, như dữ liệu từ các vệ tinh Landsat-5, Landsat-7, Landsat-8, MODIS, NOAA-AVHRR, Sentinel1 , Sentinel-2 và nhiều vệ tinh khác. Các ứng dụng của viễn thám giám sát cây trồng nói chung và giám sát lúa nói riêng đã được giới thiệu rộng rãi và được ứng dụng ngày càng nhiều [16-18]. Trong nghiên cứu này, dữ liệu viễn thám và kỹ thuật xử lý ảnh đã được sử dụng để ước tính diện tích và sản lượng lúa trong khu vực nghiên cứu qua hai mùa vụ chính là vụ Đông - Xuân và vụ Hè (vụ Mùa) năm 2019. Dữ liệu này có được bằng cách sử dụng công nghệ kỹ thuật mới, hiện đại, trong khi dữ liệu thống kê quốc gia thường được công bố chậm 5-7 tháng vào năm kế tiếp. Trong điều kiện Việt Nam, độ che phủ mây rộng khắp và lan rộng trong suốt thời gian trồng trọt các vụ lúa chính [19], vì thế dữ liệu vệ tinh quang học có những hạn chế nhất định khi nó không cung cấp đủ thông tin dưới mặt đất một cách đầy đủ do vật cản là các đám mây dày này. Điều đó đã may mắn được cải thiện và loại bỏ bởi thế hệ vệ tinh mới, hệ thống radar khẩu độ tổng hợp giao thoa SAR. SAR đã cung cấp một lợi thế với đặc tính xuyên qua các đám mây dày, điều kiện thời tiết bất lợi như bị mù, bụi khí quyển, sol khí và truyền đủ nét các thông tin mặt đất $[11,12,20]$. Trong số đó, ảnh Sentinel-1A và Sentinel-1B đã trở thành một lựa chọn phổ biến để theo dõi sinh khối nói chung và diện tích, sản lượng lúa gạo nói riêng vì chúng có sẵn, miễn phí với thời gian thu nhận trung bình (12 ngày) và độ phân giải không gian vừa phải (10 mét) [11-13]. Một số nghiên cứu và nghiên cứu về giám sát lúa gạo ở Việt Nam và các nước Đông Nam Á đã được tiến hành gần đây, chứng minh độ tin cậy, hiệu quả về thời gian, khả năng mở rộng và hiệu quả chi phí của các kỹ thuật viễn thám [18,21]. Trong công bố mới nhất của Le và các cộng sụ (2020) [9] cũng đã áp dụng công nghệ này cho vùng đồng bằng sông Hồng. Để tạo ra dữ liệu diện tích, sản lượng lúa cho khu vực nghiên cứu của khu vực nào đó qua các vụ mùa trồng lúa khác nhau, dữ liệu vệ tinh SAR Sentinel-1 trong chuỗi thời gian cần xác định đã được thu thập. Số liệu trích xuất từ công cụ này được so sánh, đánh giá kết hợp với dữ liệu thống kê và kiến thức thực địa. Đặc biệt, hai giai đoạn tương ứng với các vụ Đông - Xuân và vụ Hè đã được chọn để thu thập dữ liệu, bao gồm: từ ngày 1 tháng 1 đến ngày 15 tháng 5 cho vụ mùa Đông - Xuân; vụ Hè từ 30 tháng 5 đến 15 tháng 10 hàng năm. Trong vòng đời sinh trưởng 120-140 ngày của cây lúa, mỗi giai đoạn thu thập dữ liệu cho phép thu được 10 - 12 cảnh hình ảnh vệ tinh cho chuỗi dữ liệu, cho phép phát hiện phạm vi được tốt nhất. Kỹ thuật phân tích dữ liệu chuỗi thời gian kết hợp các giai đoạn hiện tượng của cây lúa đã mang lại sự đồng thuận rất cao với dữ liệu thống kê và số liệu thống kê $[9,18,22]$. Trong nghiên cứu trước đây của chúng tôi cho thấy mức độ tương quan giữa diện tích lúa có nguồn gốc từ vệ tinh ở cấp tỉnh và dữ liệu thống kê đã lên tới 92-94\%. Tuy vậy hình ảnh radar Sentinel-1 cũng chỉ có hiệu quả tốt và được chia sẻ dữ liệu bởi Cơ quan Vũ trụ châu Âu (European Space Agency, ESA) từ 2015 đến nay $[12,18]$. Chùm vệ tinh Sentinel-1 với hai vệ tinh Sentinel-1A và Sentinel-1B sử dụng cảm biến radar khẩu độ tổng hợp giao thoa để thu nhận tín hiệu phản hồi từ bề mặt trái đất. Tín hiệu thu nhận thể hiện độ nhám của bề mặt dưới dạng số, cho phép phân tích để đưa ra các thông tin hữu ích. Trong vòng đời của cây lúa (Hình 1), một số mốc quan trọng tính từ lúc gieo cấy tới thời điểm thu hoạch đã được ghi nhận và sử dụng để xác định mối tương quan giữa đặc tính phát triển của cây trồng này với đường biến thiên của tín hiệu phản xạ trên ảnh vệ tinh. 


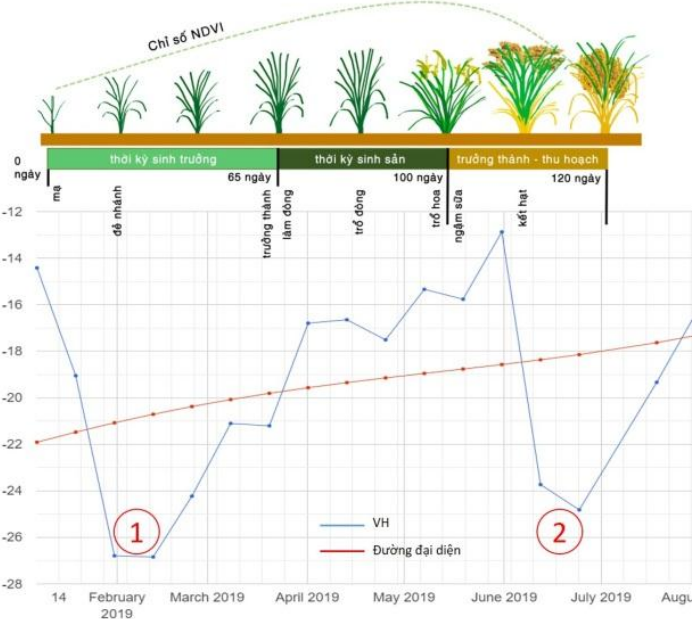

Hình 1. Sơ đồ biểu thị mối tương quan giữa đặc tính phát triển của cây lúa với đường biến thiên của tín hiệu phản xạ trên ảnh vệ tinh.

Trong hình minh họa (Hình 1), tai hai thời điểm bắt đầu (1) và kết thúc một vụ lúa (2), tín hiệu thu nhận VH trên ảnh SAR đạt mức thấp nhất (dưới $-22 \mathrm{~dB})$. Đó là các thời điểm khi bề mặt đồng ruộng hoàn toàn không có cây trồng, tương ứng với giá trị độ nhám rất thấp trên ảnh vệ tinh. Đặc biệt tại thời điểm bắt đầu mùa vụ (1), khi nước được đổ ải vào đồng cho công tác làm đất, tín hiệu phản xạ gần như đạt mức cực tiểu. Khảo sát trên ảnh vệ tinh qua các thời kỳ cho thấy tín hiệu nước trên những khu vực có canh tác lúa giảm dần theo thời gian, khi cây lúa gia tăng cả về chiều cao lẫn mật độ. Kết hợp việc nhận dạng đường đặc tính này với các tham số khác như miền giá trị tín hiệu phản xạ trên ảnh của cây lúa (từ $-12 \mathrm{~dB}$ đến $-8 \mathrm{~dB}$ ) và thời gian $\sinh$ trưởng (từ 110 đến 130 ngày, tương ứng từ thời điểm (1) đến (2) trên Hình 1), bản đồ diện tích canh tác lúa đã được thành lập với độ chính xác cao.

Kỹ thuật ước tính năng suất lúa được tiến hành dựa trên các nghiên cứu ứng dụng mô hình sinh trưởng cây lúa sử dụng hệ thống OZYZA 2000 do Viện Nghiên cứu Lúa quốc tế (IRRI) phát triển [18,21]. Mô hình (Hình 2) sử dụng tham số chính đầu vào là chỉ số mật độ lá lúa (LAI - Leaf Area Index) [21] chiết xuất từ dữ liệu vệ tinh. Chỉ số LAI đại diện cho sinh khối cây lúa, một chỉ thị quan trọng liên quan đến năng suất cuối vụ của cây trồng này. Mô hình ước tính năng suất lúa lấy chỉ số lá LAI từ dữ liệu vệ tinh [18,22], kết hợp các tham số khác như giống lúa, môi trường canh tác (nhiệt độ, lượng mưa, tốc độ gió, vòng đời cây lúa tính bằng ngày, mực nước trên đồng, phân bón, loại đất, thành phần cơ giới...) để đưa ra kết quả chỉ số năng suất cho từng điểm ảnh (pixel) trên bản đồ. Với khả năng thu nhận cùng một lúc dữ liệu của 2 vệ tinh là Sentinel-1A và Sentinel-1B, tần suất thu nhận ảnh cho cùng một khu vực là 6 ngày, cho phép nhóm nghiên cứu thu nhận từ 18-20 ảnh trong thời gian diễn ra một vụ lúa. Tần suất này hoàn toàn đáp ứng được yêu cầu giám sát sinh trưởng cây lúa từ thời điểm bắt đầu gieo trồng đến lúc thu hoạch.

Trong bài báo này, dữ liệu sản lượng lúa được thu thập từ hệ thống thống kê quốc gia từ $2000-2018$, trong khi đó số liệu lúa trích xuất từ ảnh vệ tinh SAR Sentinel-1 là 2015 - 2019. Đồng thời nguồn số liệu được xử lý thống kê về mối tương quan số liệu cho giai đoạn (2015 - 2018) có cùng đồng thời số liệu ở 2 nguồn thống kê và vệ tinh SAR Sentinel-1 (Hình 3). Số liệu sản lượng lúa là khởi đầu cho việc tính toán mức phát thải các chất ô nhiễm do đốt rơm rạ ở bước tiếp theo.

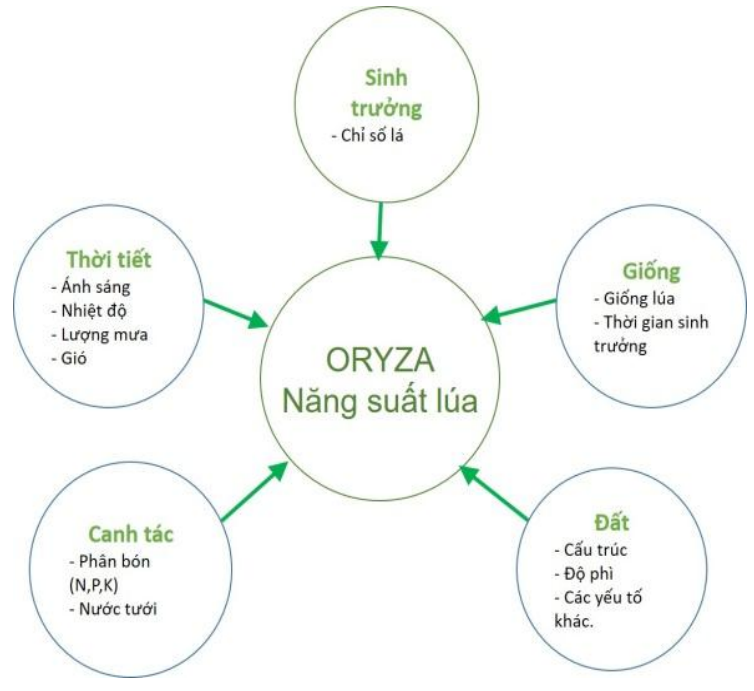

Hình 2. Mô hình sinh trưởng cây lúa sử dụng hệ thống OZYZA 2000. 


\subsection{Phương pháp kiểm kê khí thải}

Khí thải từ hoạt động đốt sinh khối được ước tính dựa trên sản lượng sinh khối đốt và hệ số phát thải (emission factor - EF). Với bất kỳ loại đốt sinh khối, khí thải được tính toán bằng cách sử dụng công thức (1) như sau [10]:

$E m_{i j}=\sum_{j}^{n} M_{j} \times E F_{i j}$

Trong đó:

i: chất ô nhiễm i;

$\mathrm{j}$ : loại cây trồng $\mathrm{j}$;

$\mathrm{Em}_{\mathrm{ij}}$ : Lượng khí thải của chất ô nhiễm i từ loại cây trồng $\mathrm{j}$;

$\mathrm{M}_{\mathrm{j}}$ : Sản lượng sinh khối được đốt cháy tù loại cây trồng $\mathrm{j}(\mathrm{kg} / \mathrm{năm})$;

$\mathrm{EF}_{\mathrm{ij}}$ : Hệ số phát thải của chất ô nhiễm $\mathrm{i}$ từ loại cây trồng $\mathrm{j}(\mathrm{g} / \mathrm{kg})$.

Sản lượng sinh khối đốt cháy được ước tính dựa trên sản lượng cây trồng, các tỉ lệ phụ phẩm và hiệu suất đốt theo công thức (2) như sau [10]:

$$
M_{j}=P_{j} \times N_{j} \times D_{j} \times B_{j} \times \eta_{j}
$$

Trong đó:

$\mathrm{P}_{\mathrm{j}}$ : Sản lượng cây trồng ( $\left.\mathrm{kg} / \mathrm{năm}\right)$;

$\mathrm{N}_{\mathrm{j}}$ : Tỉ lệ phụ phẩm theo sản lượng (lúc vừa thu hoạch);

$\mathrm{D}_{\mathrm{j}}$ : Tỉ trọng khô của phụ phẩm;

$\mathrm{B}_{\mathrm{j}}$ : Tỉ lệ đốt phụ phẩm;

$\eta_{\mathrm{j}}$ : Hiệu suất đốt (\%).

Sản lượng rơm rạ của TĐHN được ước tính trên cơ sở dữ liệu sản xuất lúa được thu thập vào năm 2015 của Tổng cục Thống kê (số liệu chính thống, có độ tin cậy cao và cập nhật nhất hiện nay) và từ kết quả điều tra, khảo sát thực tế của tác giả [23]. Hiện nay, tại Việt Nam chưa có hệ số phát thải riêng cho rơm rạ khi đốt ngoài đồng ruộng, nên nghiên cứu này sử dụng hệ số phát thải đã được công bố từ các nghiên cứu của các nước châu Á có hoạt động sản xuất nông nghiệp như Thái Lan và Trung Quốc để ước tính lượng khí thải. Theo đó, các thông số ảnh hưởng quá trình đốt và hệ số phát thải $(\mathrm{g} / \mathrm{kg})$ của các khí thải phát ra do đốt rơm rạ trên đồng ruộng được thể qua Bảng 1.

Bảng 1. Tổng hợp các giá trị/thông số trong kiểm kê khí thải

\begin{tabular}{|c|c|c|}
\hline Hệ số phát thải & Giá trị & Nguồn tham khảo \\
\hline \multicolumn{3}{|c|}{ Các đại lượng ảnh hưởng } \\
\hline $\mathrm{N}_{\mathrm{j}}$ & 0,9 & \multirow{3}{*}{ He và cộng sự [1] } \\
\hline$D_{j}$ & 0,89 & \\
\hline$\eta_{j}$ & 0,93 & \\
\hline $\mathrm{B}_{\mathrm{j}}$ & 0,44 & Lê và cộng sự [8] \\
\hline \multicolumn{3}{|c|}{ Hệ số phát thải chất ô nhiễm $(\mathrm{g} / \mathrm{kg})$} \\
\hline $\mathrm{PM}_{10}$ & 9,1 & \multirow{9}{*}{$\begin{array}{l}\text { Lựa chọn bởi } \\
\text { Le và cộng sự [9] }\end{array}$} \\
\hline $\mathrm{PM}_{2.5}$ & 8,3 & \\
\hline $\mathrm{BC}$ & 0,51 & \\
\hline $\mathrm{CO}_{2}$ & 1.177 & \\
\hline $\mathrm{CO}$ & 93 & \\
\hline $\mathrm{SO}_{2}$ & 0,18 & \\
\hline $\mathrm{NO}_{\mathrm{x}}$ & 2,28 & \\
\hline $\mathrm{NH}_{3}$ & 4,1 & \\
\hline $\mathrm{CH}_{4}$ & 9,59 & \\
\hline
\end{tabular}

\section{Kết quả nghiên cứu và thảo luận}

\subsection{Tình hình sản suất lúa trên địa bàn thủ đô Hà Nội}

Diện tích, năng suất lúa hàng năm toàn TĐHN trong giai đoạn 2000 - 2019 được thống kê và trình bày ở Hình 3 , trong đó số liệu 2000 2018 là số liệu từ niên giám thống kê quốc gia, số liệu 2019 là số liệu xử lý ảnh vệ tinh SAR Sentinel-1. Nếu phân chia giai đoạn gần 2 thập kỷ này thành 2 giai đoạn nhỏ (trước 2007 và sau 2009) đều cho thấy cả diện tích canh tác và sản lượng lúa thu được trên địa bàn TĐHN có $\mathrm{xu}$ hướng giảm xuống. Diện tích trồng lúa có xu hướng giảm dần từ 54.200 ha (năm 2000) xuống còn 43.300 ha (năm 2007). Sản lượng lúa ở giai đoạn này cũng có xu thế giảm dần từ 224,6 nghìn tấn (năm 2000) xuống còn 184,2 nghìn tấn (năm 2007). Năm 2008, theo Nghị quyết số 15/2008/NQ-QH12 của Quốc hội, từ 01/08/2008 TĐHN được mở rộng địa giới hành chính. Theo đó TĐHN sẽ mở rộng diện tích gấp 3,6 so với diện tích TĐHN lúc bấy giờ. Địa giới hành chính sau khi mở rộng bao gồm: TĐHN lúc đó, toàn bộ 
tỉnh Hà Tây, huyện Mê Linh (Vĩnh Phúc) và 4 xã của huyện Lương Sơn (Hòa Bình). Tổng diện tích của TĐHN mới hơn $3.300 \mathrm{~km}^{2}$. Điều đáng nói là phần diện tích mở rộng có sự góp mặt của các địa phương có hoạt động sản xuất nông nghiệp ấn tượng, năng suất cao của vùng.

Kết quả dẫn đến tăng đột biến về diện tích đất nông nghiệp toàn TĐHN lên 206.900 ha (Hình 3a). Đi kèm với sự gia tăng diện tích canh tác, sản lượng lúa trong năm 2008 cũng lập tức được thống kê và cho thấy đã tăng gấp sáu lần so với năm 2007, lên 1.177.800 tấn. Những năm sau đó, sản lượng lúa dao động quanh mức 1,1 - 1,2 triệu tấn. Xu hướng chung vẫn có quá trình suy giảm về diện tích giao trồng (xuống còn 177 nghìn ha) và sản lượng lúa thu hoạch (khoảng 1,026 nghìn tấn) vào năm 2019. Diện tích đất trồng lúa của TĐHN được tập trung chủ yếu ở các huyện ngoại thành như Ba Vì, Ứng Hòa, Sóc Sơn, Phú Xuyên, Thanh Oai, Mỹ Đức và Thường Tín. Đây cũng phần lớn là các địa phương mới được sát nhập về TĐHN sau 2008.

Như vậy, mặc dù diện tích trồng lúa có xu hướng bị thu hẹp, song quá trình áp dụng khoa
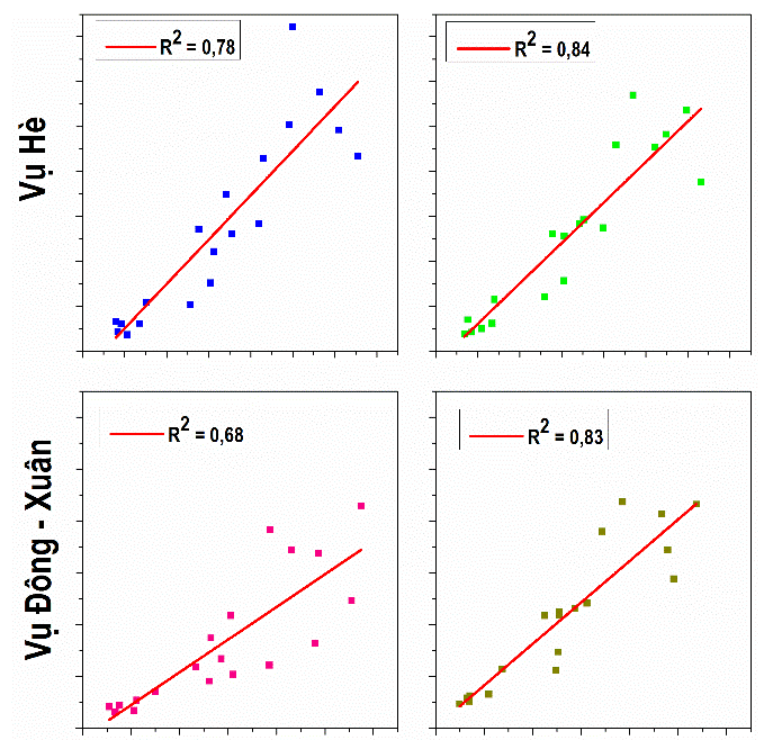

2015

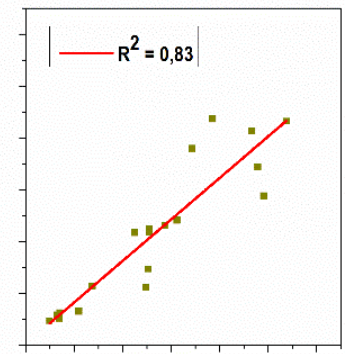

2016 học kỹ thuật trong việc cải tiến giống lúa, kỹ thuật trồng và chăm sóc tiên tiến đã dẫn đến sản lượng lúa vẫn được duy trì. Và nhờ đó năng suất lúa trên địa bàn $\mathrm{T} Đ H N$ không ngừng gia tăng hàng năm, đạt chỉ số gần 6 tấn/ha (Hình $3 b$ ), thuộc diện cao nhất vùng Đông Nam Á $[9,18]$.

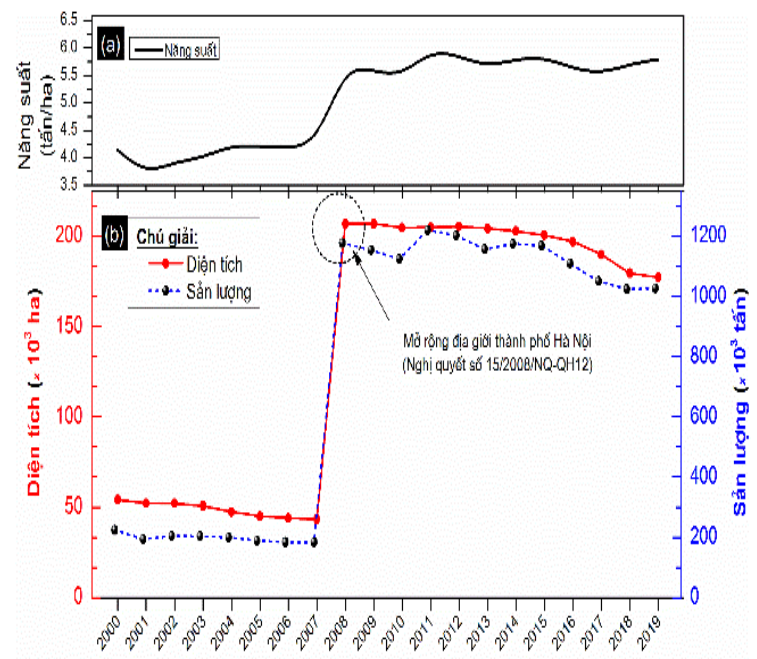

Hình 3. Diện tích gieo trồng, sản lượng và năng suất lúa của TĐHN, giai đoạn 2000-2019.
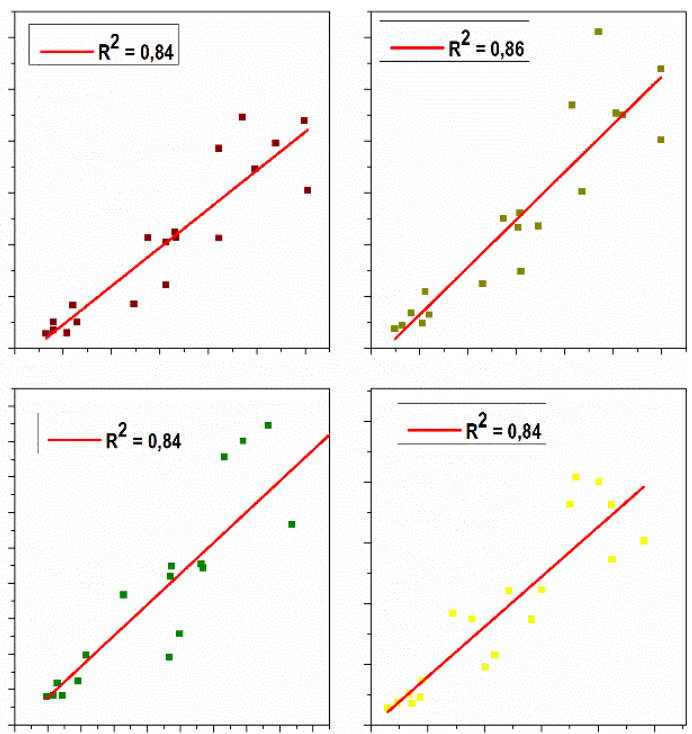

2017

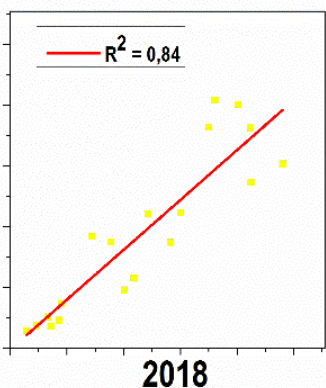

2018

Hình 4. Mức tương quan giữa số liệu vệ tinh SAR Sentinel-1 (trục tung) và số liệu thống kê quốc gia (trục hoành). 
Bảng 2. Kết quả kiểm kê lượng rơm rạ đốt trên đồng ruộng và tổng khí phát thải từ hoạt động đốt rơm rạ trên địa bàn thủ đô Hà Nội năm 2019 (đơn vị: tấn)

\begin{tabular}{|l|l|l|l|l|l|l|l|l|l|l|}
\hline Huyện/Quận & Rơm rạ & $\mathrm{BC}$ & $\mathrm{PM}_{10}$ & $\mathrm{PM}_{2.5}$ & $\mathrm{CO}_{2}$ & $\mathrm{CO}$ & $\mathrm{SO}_{2}$ & $\mathrm{NO}_{\mathbf{x}}$ & $\mathrm{NH}_{3}$ & $\mathrm{CH}_{4}$ \\
\hline Ba Vì & $31.548,2$ & 16,1 & 287,1 & 261,9 & $37.132,3$ & $2.934,0$ & 5,7 & 71,9 & 129,3 & 302,5 \\
\hline Chương Mỹ & $45.052,4$ & 23,0 & 410,0 & 373,9 & $53.026,7$ & $4.189,9$ & 8,1 & 102,7 & 184,7 & 432,1 \\
\hline Đan Phượng & $3.959,1$ & 2,0 & 36,0 & 32,9 & $4.659,8$ & 368,2 & 0,7 & 9,0 & 16,2 & 38,0 \\
\hline Đông Anh & $22.412,4$ & 11,4 & 204,0 & 186,0 & $26.379,4$ & $2.084,4$ & 4,0 & 51,1 & 91,9 & 214,9 \\
\hline Gia Lâm & $8.780,1$ & 4,5 & 79,9 & 72,9 & $10.334,1$ & 816,5 & 1,6 & 20,0 & 36,0 & 84,2 \\
\hline Hoài Đức & $5.769,6$ & 2,9 & 52,5 & 47,9 & $6.790,8$ & 536,6 & 1,0 & 13,2 & 23,7 & 55,3 \\
\hline Mê Linh & $5.306,4$ & 2,7 & 48,3 & 44,0 & $6.245,6$ & 493,5 & 1,0 & 12,1 & 21,8 & 50,9 \\
\hline Mỹ Đức & $50.517,1$ & 25,8 & 459,7 & 419,3 & $59.458,6$ & $4.698,1$ & 9,1 & 115,2 & 207,1 & 484,5 \\
\hline Phú Xuyên & $47.533,3$ & 24,2 & 432,6 & 394,5 & $55.946,7$ & $4.420,6$ & 8,6 & 108,4 & 194,9 & 455,8 \\
\hline Phúc Thọ & $15.990,7$ & 8,2 & 145,5 & 132,7 & $18.821,1$ & $1.487,1$ & 2,9 & 36,5 & 65,6 & 153,4 \\
\hline Quốc Oai & $21.560,0$ & 11,0 & 196,2 & 178,9 & $25.376,2$ & $2.005,1$ & 3,9 & 49,2 & 88,4 & 206,8 \\
\hline Sóc Sơn & $43.911,3$ & 22,4 & 399,6 & 364,5 & $51.683,6$ & $4.083,7$ & 7,9 & 100,1 & 180,0 & 421,1 \\
\hline Thạch Thất & $24.868,1$ & 12,7 & 226,3 & 206,4 & $29.269,8$ & $2.312,7$ & 4,5 & 56,7 & 102,0 & 238,5 \\
\hline Thanh Oai & $38.676,1$ & 19,7 & 352,0 & 321,0 & $45.521,7$ & $3.596,9$ & 7,0 & 88,2 & 158,6 & 370,9 \\
\hline Thường Tín & $23.704,2$ & 12,1 & 215,7 & 196,7 & $27.899,8$ & $2.204,5$ & 4,3 & 54,0 & 97,2 & 227,3 \\
\hline Từ Liêm & $1.069,6$ & 0,5 & 9,7 & 8,9 & $1.258,9$ & 99,5 & 0,2 & 2,4 & 4,4 & 10,3 \\
\hline Ứng Hòa & $59.369,0$ & 30,3 & 540,3 & 492,8 & $69.877,3$ & $5.521,3$ & 10,7 & 135,4 & 243,4 & 569,3 \\
\hline Hà Đông & $2.763,4$ & 1,4 & 25,1 & 22,9 & $3.252,5$ & 257,0 & 0,5 & 6,3 & 11,3 & 26,5 \\
\hline Hoàng Mai & 150,1 & 0,1 & 1,4 & 1,2 & 176,7 & 14,0 & 0,0 & 0,3 & 0,6 & 1,4 \\
\hline Long Biên & 945,2 & 0,5 & 8,6 & 7,8 & $1.112,4$ & 87,9 & 0,2 & 2,2 & 3,9 & 9,1 \\
\hline Tây Hồ & 46,3 & 0,0 & 0,4 & 0,4 & 54,5 & 4,3 & 0,0 & 0,1 & 0,2 & 0,4 \\
\hline Sơn Tây & $6.625,8$ & 3,4 & 60,3 & 55,0 & $7.798,5$ & 616,2 & 1,2 & 15,1 & 27,2 & 63,5 \\
\hline Tổng & $460.558,1$ & 234,9 & $4.191,1$ & $3.822,6$ & $542.076,9$ & $42.831,9$ & 82,9 & $1.050,1$ & $1.888,3$ & $4.416,8$ \\
\hline
\end{tabular}

3.2. Khả năng cung cấp dũ liệu của SAR Sentinel-1

Để kiểm chứng khả năng cung cấp (độ chính xác tương đối) dữ liệu bằng công cụ ảnh vệ tinh SAR Sentinel-1, nghiên cứu này sử dụng độ chồng lấp dữ liệu giai đoạn 2015 - 2018 thu được qua chuỗi số liệu thống kê quốc gia và chuỗi số liệu xử lý ảnh vệ tinh SAR Sentinel-1.

Kết quả mối tương quan được biểu diễn qua Hình 4 cho thấy mức tương quan $\left(\mathrm{R}^{2}\right)$ có giá trị trong khoảng $0,78-0,86$. Xu hướng giá trị độ tương quan $R^{2}$ lớn dần từ $2015-2018$, đối với vụ Đông - Xuân tăng từ $\mathrm{R}^{2}=0,78-0,86$, vụ Hè tăng từ $\mathrm{R}^{2}=0,68-0,84$. Điều đó cho thấy chất lượng giải mã đối tượng của SAR Sentinel-1 được nâng cấp dần. Giá trị $\mathrm{R}^{2}$ trong vụ mùa lớn hơn ở vụ Đông - Xuân vì điều kiện thời tiết (lượng mưa, độ che phủ bóng mây, aerosol) ít cản trở hơn $[12,14]$. Như vậy có thể thấy mức độ tương quan này là đủ tốt và có thể sử dụng được cho việc ước tính sản lượng lúa địa phương qua công cụ vệ tinh SAR Sentinel-1. Kết quả này cũng cho thấy giá trị tương quan có thấp hơn kết quả nghiên cứu của Le và cộng sự (2020) [9] cho vùng đồng bằng sông Hồng, tuy nhiên trong nghiên cứu đó là sự so sánh theo không gian (địa phương cấp tỉnh), trong khi nghiên cứu này lại so sánh theo số liệu theo thời gian (từng năm, trong giai đoạn 2015 - 2018).

Kết quả mối tương quan được biểu diễn qua Hình 4 cho thấy mức tương quan $\left(\mathrm{R}^{2}\right)$ có giá trị trong khoảng $0,78-0,86$. Xu hướng giá trị độ tương quan $R^{2}$ lớn dần từ 2015 - 2018, đối với vụ Đông - Xuân tăng từ $\mathrm{R}^{2}=0,78-0,86$, vụ Hè tăng từ $\mathrm{R}^{2}=0,68-0,84$. Điều đó cho thấy chất lượng 
giải mã đối tượng của SAR Sentinel-1 được nâng cấp dần. Giá trị $\mathrm{R}^{2}$ trong vụ mùa lớn hơn ở vụ Đông - Xuân vì điều kiện thời tiết (lượng mưa, độ che phủ bóng mây, aerosol) ít cản trở hơn $[12,14]$. Như vậy có thể thấy mức độ tương quan này là đủ tốt và có thể sử dụng được cho việc ước tính sản lượng lúa địa phương qua công cụ vệ tinh SAR Sentinel-1. Kết quả này cũng cho thấy giá trị tương quan có thấp hơn kết quả nghiên cứu của Le và cộng sự (2020) [9] cho vùng đồng bằng sông Hồng, tuy nhiên trong nghiên cứu đó là sự so sánh theo không gian (địa phương cấp tỉnh), trong khi nghiên cứu này lại so sánh theo số liệu theo thời gian (từng năm, trong giai đoạn 2015 - 2018).

\subsection{Tổng lương khi thải phát sinh tù hoạt động đốt rơm rạ ngoài đồng ruộng trên địa bàn thủ đô Hà Nội}

Để ước tính lượng chất thải phát sinh do hoạt động đốt rơm rạ ngoài đồng ruộng trên địa bàn TĐHN, nghiên cứu này sử dụng dữ liệu vệ tinh SAR Sentinel-1 năm 2019. Kết quả xử lý ảnh vệ tinh về diện tích, năng suất lúa vụ Đông - Xuân và vụ Mùa năm 2019 trên địa bàn TĐHN được trình bày lần lượt ở Hình 5 và Hình 6 . Từ đó sử dụng công thức (1) và (2) để tính toán tổng lượng khí thải được thề hiện qua Bảng 2. Kết quả kiểm kê khí thải năm 2019 ở Bảng 2 cho thấy lượng
$\mathrm{CO}_{2}$ là thành phần phát thải lớn nhất (543 nghìn tấn; chiếm $90 \%$ ), tiếp đó là CO (43 nghìn tấn; chiếm $7 \%$ ), và tồng lượng các chất ô nhiễm khác như $\mathrm{PM}_{10}, \mathrm{PM}_{2.5}, \mathrm{BC}, \mathrm{SO}_{2}, \mathrm{NO}_{x}, \mathrm{NH}_{3}$ và $\mathrm{CH}_{4}$ chỉ chiếm lượng nhỏ khoảng $3 \%$ còn lại. Điều đáng lo ngại là các chất ô nhiễm nói trên có những chất là tác nhân gây nên hiệu ứng nhà kính, góp phần gây xấu thêm tình trạng biến đổi khí hậu vốn đã cấp bách như hiện nay. Các khí thải từ đốt rơm rạ trên cánh đồng (năm 2019) tập trung nhiều ở các huyện Ứng Hòa, Mỹ Đức, Phú Xuyên (Hình 7). Nguyên do là sự khác nhau về diện tích trồng và sản xuất lúa gạo và tỷ lệ đốt rơm rạ ngoài đồng của các địa phương. Tổng lượng các chất ô nhiễm có mối quan hệ chặt chẽ với tình hình sản xuất lúa gạo và tỷ lệ đốt rơm rạ. Nói cách khác, địa phương có năng suất, sản lượng lúa và tỷ lệ đốt rơm cao thì tổng lượng các chất khí phát sinh càng lớn tương ứng. Chất lượng môi trường không khí vùng đô thị TĐHN vì vậy cũng sẽ bị ảnh hưởng lớn bởi các chất khí phát sinh trong hoạt động đốt rơm rạ ở vùng ngoại ô. Phần tổng quan đã cho thấy, để giảm thiểu sai số của phương pháp kiểm kê khí thải từ hoạt động đốt rơm rạ có thể thực hiện được nhờ một số giải pháp về đầu tư xây dựng, cập nhật cơ sở dữ liệu phát sinh nguồn rơm rạ thải bỏ và bị đốt, đầu tư vào hệ thống quan trắc và kiểm soát ô nhiễm không khí, hơn nữa cần thiết xây dựng được bộ hệ số phát thải chuẩn cho địa phương.
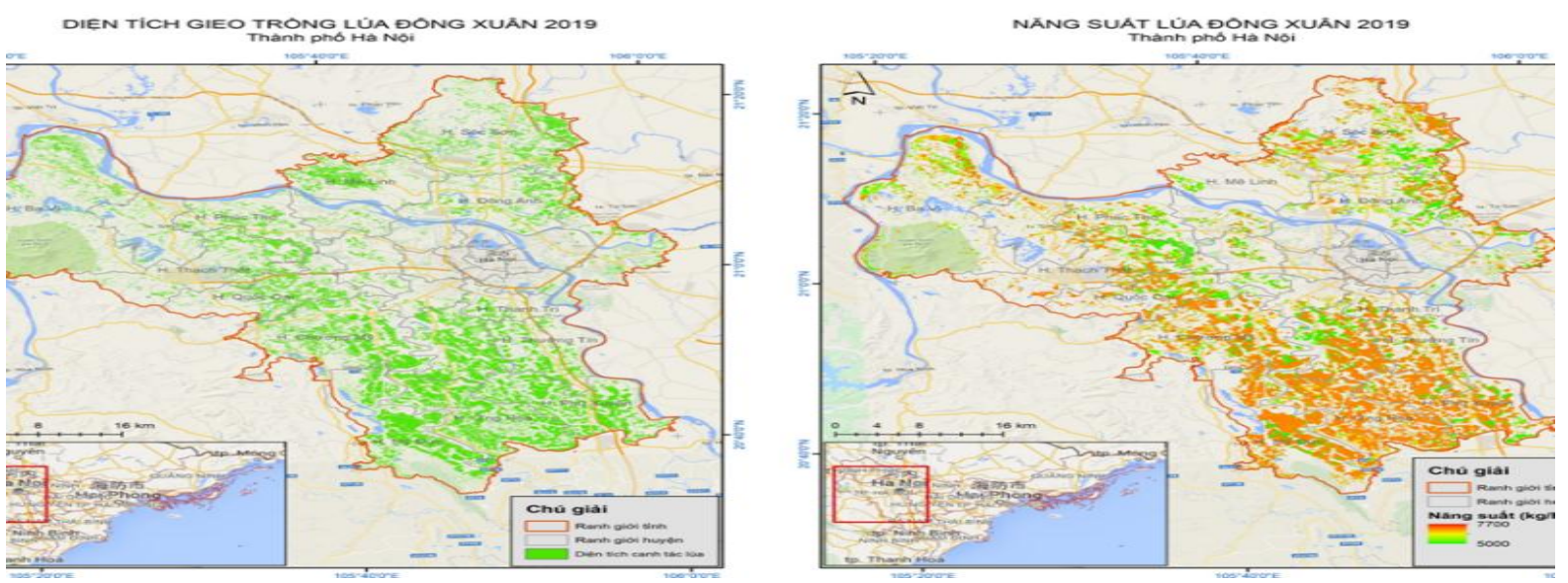

Hình 5. Bản đồ diện tích, năng suất lúa vụ Đông - Xuân trên địa bàn thủ đô Hà Nội năm 2019. 

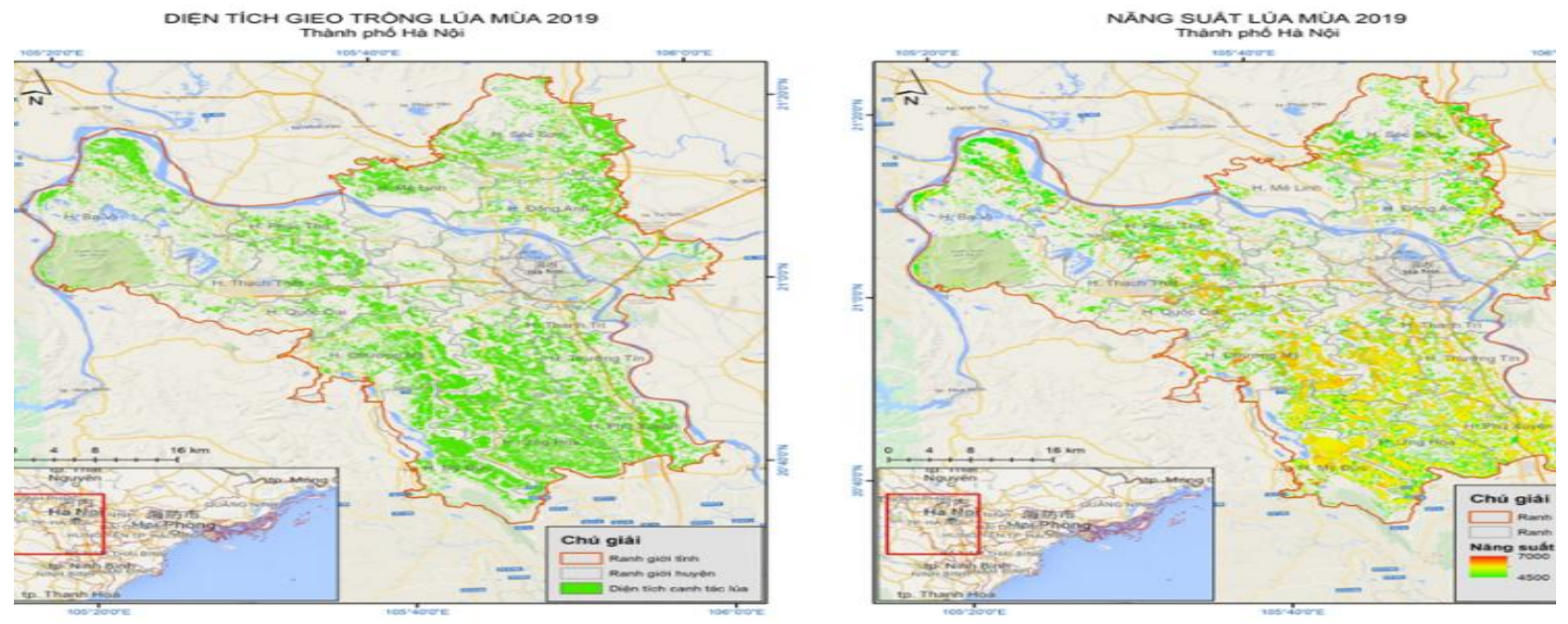

Hình 6. Bản đồ diện tích, năng suất lúa vụ Mùa trên địa bàn thủ đô Hà Nội năm 2019.

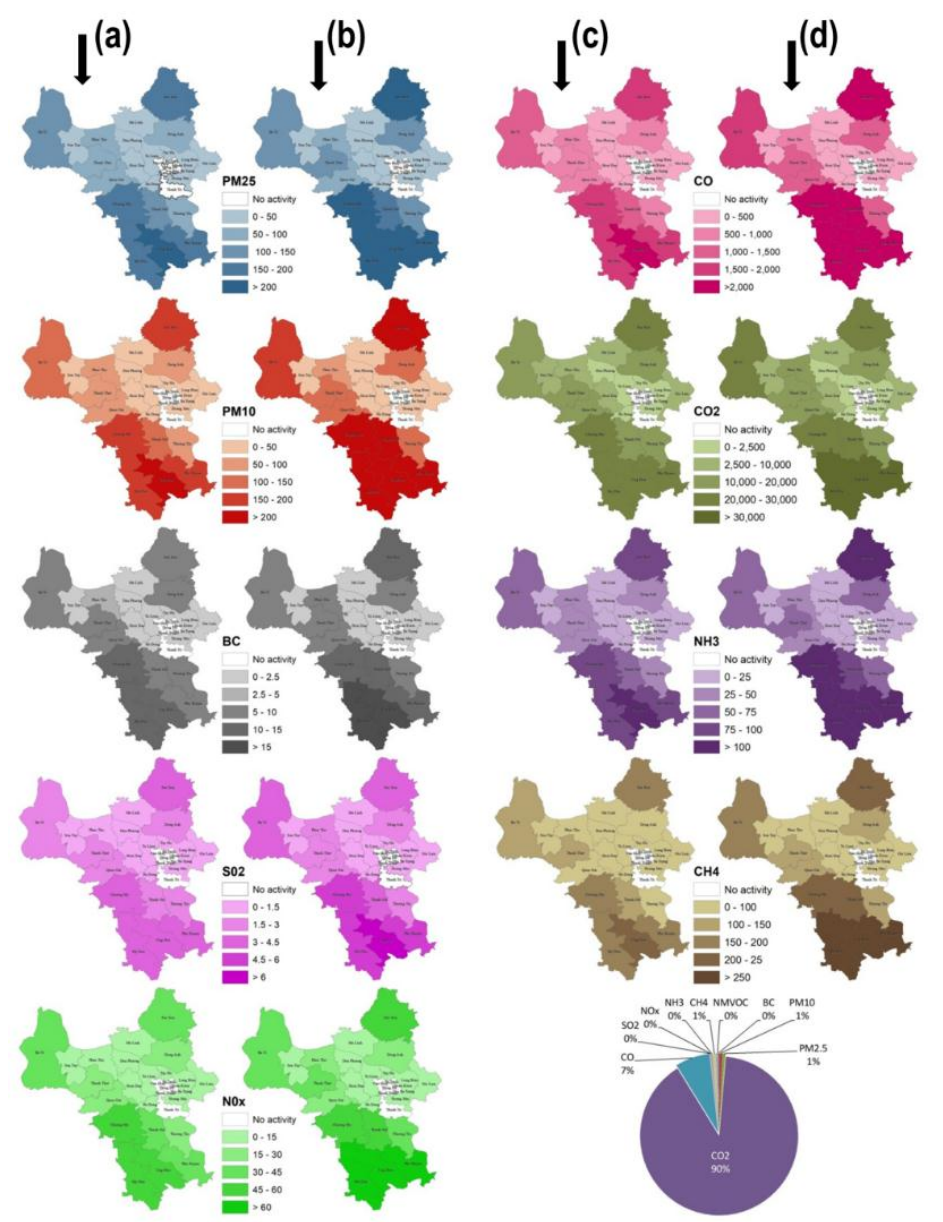

Hình 7. Phân bố tổng lượng khí thải do đốt rơm rạ ngoài đồng ruộng trên địa bàn các quận/huyện TĐHN theo vụ Đông - Xuân (a, c), vụ Mùa (b, d) năm 2019. 


\section{Kết luận}

Đốt rơm rạ trên các cánh đồng đã và đang trở thành vấn đề nghiêm trọng, cần được quan tâm trong quản lý chất lượng môi trường không khí xung quanh. Cần phải lập kế hoạch về quản lý và đẩy mạnh nghiên cứu sử dụng rơm rạ sau khi thu hoạch, tránh những vấn đề môi trường phát sinh từ đốt rơm rạ trên đồng ruộng đã và đang phổ biến như hiện nay. Việc giải đoán ảnh vệ tinh SAR Sentinel-1 hoàn toàn có thể đáp ứng được mục đích kiểm kê diện tích, sản lượng gieo trồng lúa để có thể ước tính được lượng rơm rạ thải bỏ ngoài đồng ruộng. Kết quả ảnh vệ tinh sẽ cho chúng ta tiên lượng được lượng khí thải phát sinh do hoạt động đốt rơm rạ ngoài đồng ruộng gây nên để qua đó có chính sách quản lý sớm, phù hợp nhằm giảm thiểu ô nhiễm môi trường.

Theo kết quả tính toán được vào năm 2019, với lượng rơm rạ thải bỏ và bị đem đốt trên đồng ruộng ở địa bàn $\mathrm{T} Đ H N$ vào khoảng 460 nghìn tấn, tạo nên tổng lượng của một số chất gây ô nhiễm bao gồm $\mathrm{PM}_{2.5}, \mathrm{PM}_{10}, \mathrm{BC}, \mathrm{CO}, \mathrm{CO}_{2}, \mathrm{SO}_{2}$, $\mathrm{NO}_{\mathrm{x}}, \mathrm{NH}_{3}$ và $\mathrm{CH}_{4}$, tương ứng là 3.822, 4.191, $235,42.832,542.000,83,1.000,1.888$, và 4.400 tấn. $\mathrm{CO}_{2}$ là thành phần phát sinh lớn nhất (gần $90 \%$ ), sau đó CO chiếm khoảng $7 \%$, và những khí thải khác chỉ chiếm khoảng $3 \%$ còn lại. Khí thải sinh từ đốt rơm rạ tập trung chủ yếu ở các huyện ngoại thành như Ứng Hòa, Mỹ Đức, và Phú Xuyên nơi có diện tích trồng lúa lớn. Kết quả nghiên cứu này cung cấp dữ liệu cơ bản để kiểm kê phát thải của TĐHN và có thể được sử dụng trong quản lý chất lượng môi trường không khí ở Việt Nam.

\section{Lời cảm ơn}

Nghiên cứu này được tài trợ bởi Quỹ phát triển khoa học và công nghệ Quốc gia (NAFOSTED) trong đề tài mã số 105.082018.04.

\section{Tài liệu tham khảo}

[1] M. He, J. Zheng, S. Yin, Y. Zhang, Trends, temporal and spatial characteristics, and uncertainties in biomass burning emissions in the Pearl River Delta, China, Atmospheric Environment, $45 \quad$ (2011) 4051-4059. https://doi.org/10.1016/j.atmosenv.2011.04.016

[2] MONRE, Environemtal status of Vietnam in 2016: Urban environment issuse, Ministry of Natural Resources and Environment (MONRE), Hanoi, 2017. (in Vietnamese).

[3] H.A. Le, N.T.T. Hạnh, L.T. Linh, Estimated gas emission from burning rice straw in open fields in Thái Bình province, VNU Journal of Science: Earth and Environmental Sciences 2 (2013) 26-33. (in Vietnamese).

[4] N.M. Dung, An Estimation of Air Pollutant Emissions from Open Rice Straw Burning in the Red River Delta, Journal of Science and Development 10 (2012) 190-198 (in Vietnamese).

[5] P.D. Agustian, N.T.K. Oanh, Assessment of biomass open burning emissions in Indonesia and potential climate forcing impact, Atmospheric Environment 78 (2013) 250-258. https://doi.org/10.1016/j.atmosenv.2012.10.016

[6] N.T.K. Oanh, B.T. Ly, D. Tipayarom, B.R. Manandhar, P. Prapat, C.D. Simpson, L.-J.S. Liu, Characterization of particulate matter emission from open burning of rice straw, Atmospheric Environment 45 (2011) 493-502. https://doi.org/10.1016/j.atmosenv.2010.09.023

[7] D.M. Cuong, H.A. Le, H.X. Co, Calculation of Gas Emission from Rice Straw Open Burning in Ninh Binh Province for 2010 - 2015 Period and Proposal of Mitigation Solutions VNU Journal of Science: Earth and Environmental Sciences 32 (2016) 70 76 (in Vietnamese).

[8] H.A. Le, T.V. Anh, N.T.Q. Hung, Ais pollutants estimated from rice straw open burning in Hanoi, Journal of Agricultural Science and Technology, 5 (2017) 101 - 107 (in Vietnamese).

[9] H.A. Le, D.M. Phuong, L.T. Linh, Emission inventories of rice straw open burning in the Red River Delta of Vietnam: Evaluation of the potential of satellite data, Environmental Pollution 260 (2020) 113972-113986. https://doi.org/10.1016/j.envpol.2020.113972.

[10] K. Thongchai, N.T.K. Oanh, Development of spatial and temporal emission inventory for crop residue field burning, Environmental Modeling \& Assessment, 16 (2011) 453-464. https://doi.org/10.1007/s10666-010-9244-0 
[11] N.T. Luan, N.T. Hung, V.D. Cuong, N.T. Huyen, P.Q. Son, Building the flood maps based on Radar remote sensing data applying for the downstream of the Tra Khuc River and the Ve River in Quang Ngai province, Journal of Water Resources and Environmental Engineering, 39 (2017) 21-28 (in Vietnamese).

[12] N.V. Viet, N.Q. Hiep, A new approach to data processing of Sentinel-1 radar remote sensing image on the establishment of reservoir characteristic curve Journal of Water Resources and Environmental Engineering, (2019) 155-162 (in Vietnamese).

[13] L.V. Trung, N.T. Co, Assessment of capacity of using sentinel-1 images in monitoring land subsidence in Ho Chi Minh City Science and Technology Development Journal (Science of the Earth \& Environment), 2 (2018) 19-25 (in Vietnamese).

[14] N.V. Thi, N.D. Duong, T.Q. Bao, The relation between backscatter of Sentinel-1 radar image and NDVI sentinel-2 optical image: Case study of dipterocarp forest in Dak Lak province, Journal of Agricultural Science and Technology 3 (2018) 167-176 (in Vietnamese).

[15] B. Wu, J. Meng, Q. Li, F. Zhang, X. Du, N. Yan, Latest Development of "CropWatch" - And Global Crop Monitoring System with Remote Sensing, Advances in Earth Science, 25 (2010) 1013 -1022.

[16] L. Busetto, S. Casteleyn, C. Granell, M. Pepe, M. Barbieri, M. Campos-Taberner, R. Casa, F. Collivignarelli, R. Confalonieri, A. Crema, Downstream services for rice crop monitoring in Europe: From regional to local scale, IEEE Journal of Selected Topics in Applied Earth Observations and Remote Sensing, 10 (2017) 5423-5441. https://doi.org/10.1109/JSTARS.2017.2679159

[17] M.K. Gumma, P.S. Thenkabail, A. Maunahan, S. Islam, A. Nelson, Mapping seasonal rice cropland extent and area in the high cropping intensity environment of Bangladesh using MODIS $500 \mathrm{~m}$ data for the year 2010, ISPRS Journal of
Photogrammetry and Remote Sensing, 91 (2014) 98-113. https://doi.org/10.1016/j.isprsjprs.2014.02.007

[18] T.D. Setiyono, E.D. Quicho, F.H. Holecz, N.I. Khan, G. Romuga, A. Maunahan, C. Garcia, A. Rala, J. Raviz, F. Collivignarelli, L. Gatti, M. Barbieri, D.M. Phuong, V.Q. Minh, Q.T. Vo, A. Intrman, P. Rakwatin, M. Sothy, T. Veasna, S. Pazhanivelan, M.R.O. Mabalay, Rice yield estimation using synthetic aperture radar (SAR) and the ORYZA crop growth model: development and application of the system in South and Southeast Asian countries, International Journal of Remote Sensing, 40 (2019). https://doi.org/10.1080/01431161.2018.1547457

[19] R.E. Huke, Rice area by type of culture: South, Southeast, and East Asia, International Rice Research Institute., Manila, Philippines, 1982.

[20] R. Dwivedi, B. Rao, S. Kushwaha, The Utility of Day-and-Night Observation and Cloud-Penetration Capability of ERS-1 SAR Data for Detection of Wetlands, Geocarto International, 15 (2000) 7-12. https://doi.org/10.1080/10106040008542134

[21] A. Nelson, T. Setiyono, A. Rala, E. Quicho, J. Raviz, P. Abonete, A. Maunahan, C. Garcia, H. Bhatti, L. Villano, Towards an operational SARbased rice monitoring system in Asia: Examples from 13 demonstration sites across Asia in the RIICE project, Remote Sensing, 6 (2014) 1077310812. https://doi.org/10.3390/rs61110773

[22] T. Le Toan, F. Ribbes, L.-F. Wang, N. Floury, K.H. Ding, J.A. Kong, M. Fujita, T. Kurosu, Rice crop mapping and monitoring using ERS-1 data based on experiment and modeling results, IEEE Transactions on Geoscience and Remote Sensing, 35 (1997) 41-56. https://doi.org/10.1109/36.551933

[23] T.V. Anh, Estimated gas emission of straw open burning in rice field of Hanoi, Master thesis in advance program. VNU University of Science, (2014) Hanoi (in Vietnamese). 